\title{
"REGULAMENTOS SOBRE O SERVICYO DOS CRIADOS: UM ESTUDO SOBRE O RELACIONA- MENTO ESTADO E SOCIEDADE NO RIO GRANDE DO SUL (1887-1889)."
}

\author{
Margaret Marchiori Bakos
}

Esta pesquisa investiga as relações de trabalho no Rio Grande do Sul, no período entre os anos de 1887-1889.

Os regulamentos de serviços de criados, adotados em diversos municípios gaúchos, no período, evidenciam a necessidade de intervenção do Estado, através das Câmaras Municipais, na organização do relacionamento empregado/empregador, gerado, principalmente, a partir das libertações de escravos negros.

\section{O Rio Grande do Sul frente a iminente libertação dos escravos.}

A abolição da escravatura torna-se uma medida impositiva no Brasil, a partir de meados do século XIX. A pressão externa e a modernização incipiente no país atestam a sua necessidade. Entretanto, alguns porta-vozes da opinião pública manifestam temor diante da libertação dos escravos. Eles alertam para a desorganização do trabalho que pode seguir-se ao fato e à perturbação da ordem pública, que fatalmente ocorrerá.

A solução da problemática, segundo o positivismo, consiste no encaminhamento do liberto para o trabalho. A necessidade de integrar o proletariado à sociedade industrial pode ser identificada no discurso de Júlio de Castilhos:

"Libertar os escravos é arrancá-los à erploração secular de que tem sido vítima a raça oprimida, que lançou, com o seu suor e seu sangue, os primeiros fundamentos da nacionalidade brasileira. 
O problema é complexo, dissemo-lo; e, ao vir tomar parte na comunhão brasileira a grande massa de libertos, faz-se mister cercá-los de cuidados e garantias, a fim de que a liberdade consagrada na lei não continue a ser iludida pela opressão sistematizada dos chefes práticos da indústria.

Orande perigo nesta questão está em que se prolongue o regime de exploração do trabalhador.

De um lado, a situação do proletariado liberto em face das novas relações que o vão ligar à comunidade; de outro a organização da indústria, sob novas bases, de harmonia com a sua destinação social, reclamam, daqueles a quem incumbe a futura reorganização da nossa Pátria, a mais profunda meditação.

Ao legislador cumpre, pois, regular por tal forma a nova situação dos libertos em face dos chefes agrícolas, que, em prejuizo destes, não possa perigar a liberdade dos primeiros."1

A documentação oficial do período revela que as Assembléias Municipais apresentam, ao longo do periodo entre 1887 e 1889, uma série de leis, que visam regularizar as relações de trabalho urbano e rural no Rio Grande do Sul.

Cerca de dezoito municípios gaúchos obtêm, na época, regulamentos sobre o trabalho da criadagem no seu território.

No quadro a seguir, discrimina-se o número de escravos existentes nos municípios que adotam, nas suas posturas, os regulamenos de serviço dos criados. Observa-se ainda as atividades dos escravos negros, na província, no decorrer do ano de 1887.2 (Ver quadro no 1)

\section{Quadro n? 1}

Número de escravos nos municípios do Rio Grande do Sul e as suas atividades, conforme inscrição na matrícula encerrada a 30 de março de 1887.2 
"Regulamentos Sobre o Serviço...

\begin{tabular}{|c|c|c|c|c|c|c|}
\hline \multirow{2}{*}{$\begin{array}{c}\text { Localidade } \\
\text { no }\end{array}$} & \multirow{2}{*}{$\begin{array}{l}\text { No Total de } \\
\text { escravos }\end{array}$} & \multicolumn{5}{|c|}{ Atividades } \\
\hline & & Agricola & Artística & Jornaleiro & sem & Atividade \\
\hline Rio Grande & 844 & 201 & 23 & 620 & & - \\
\hline Pelotas & 338 & 24 & 14 & 300 & & - \\
\hline Sto Antônio & & & & & & \\
\hline da Patrulha & 252 & 149 & 3 & 100 & & - \\
\hline Jaguarão & 142 & 73 & 48 & 21 & & - \\
\hline Cacimbinhas & 112 & 7 & 1 & 104 & & - \\
\hline Porto Alegre & 58 & 13 & 2 & 43 & & - \\
\hline Camaquã & 35 & 18 & 17 & - & & - \\
\hline S. Francisco & & & & & & \\
\hline de Assis & 12 & 6 & - & 6 & & - \\
\hline Cachoeira & 464 & 163 & 209 & 92 & & - \\
\hline Passo Fundo & 28 & 9 & 1 & 14 & & 4 \\
\hline Sta. Vitória & & & & & & \\
\hline do Palmar & 255 & 109 & 2 & 144 & & - \\
\hline Sta. Maria & 17 & 9 & 5 & 3 & & - \\
\hline Itaqui & 0 & - & - & - & & - \\
\hline Sto. Ângelo & 73 & 34 & - & 39 & & - \\
\hline Gravataí & 274 & 143 & 87 & 44 & & - \\
\hline Cruz Alta & 131 & 48 & - & 83 & & - \\
\hline Santiago & 8 & 2 & 1 & 5 & & - \\
\hline Piratini & 391 & 33 & 207 & 61 & & - \\
\hline
\end{tabular}

De acordo com os dados apresentados, no quadro n० 1, verifica-se que é muito variado o número de escravos existentes nos municípios. Por exemplo, em Rio Grande encontram-se 844 escravos. Isto pode ser considerado um número elevado ao comparar-se o dado com o número de escravos apontados em Porto Alegre (58), ou Santiago (8) e Itaqui com nenhum escravo registrado.

Muito embora alguns desses municípios possuissem poucos ou nenhum escravo também se preocupavam em incluir, em suas posturas municipais, cláusulas que regulamentavam os serviços de criados. 
Conclui-se do fato que os regulamentos de serviço não visam apenas ao trabalho do escravo, uma vez liberto, mas sim a uma população obreira livre. Entre ela pode-se encontrar, além dos negros ex-escravos, também mulatos e brancos.

\section{Os regulamentos sobre o serviço dos criados.}

O primeiro regulamento de trabalho dos criados a ser aprovado pertence a cidade de Pelotas.

As Câmaras Municipais de Porto Alegre, Pelotas, Itaqui, Santo Ângelo, São Luiz Gonzaga, Quaraí, Gravataí e Cruz Alta copiam o mesmo regulamento, sem acrescentar-lhe praticamente nenhuma alteração.

O regulamento de Pelotas possui onze artigos e considera como criados "para efeitos da postura todos os indivíduos de condução livre de ambos os sexos que, mediante salário mensal, empregam-se como caixeiros, copeiros, cozinheiros, criados de serviço, amas de leite e amas secas." 3 (Ver quadro no 2)

A Câmara Municipal deve ter dois livros especiais. No primeiro anota-se o nome do criado, idade, naturalidade, filiação e ocupação. No outro, registra-se todos os contratos, notas e observações sobre o criado, que devem ser rubricadas pelo Presidente.

A Câmara fornece, mediante pagamento, cadernetas onde devem ser lançados os nomes dos contratantes e as suas residências. Os contratadores devem anotar na caderneta os pormenores referentes ao contrato de trabalho dos criados, como o salário, o tempo de serviço, etc.

O contratador somente pode despedir criados, mediante aviso prévio de dez dias. Com exceção nos casos de embriaguês, enfermidade, falta de respeito e/ou negligência do criado.

Para as amas de leite é obrigatório submeter-se a exame de saúde, feito por médico da Câmara Municipal, antes de assumir um emprego.

O contratado também tem que dar aviso prévio, de três dias, para poder abandonar o trabalho, salvo casos em que sofrer enfermidade ou maus tratos. 
Quadro n० 2

Conceito de criado utilizado nos regulamentos de serviço dos criados das Câmaras Municipais do Rio Grande do Sul.

1887-1889

\begin{tabular}{|c|c|c|c|}
\hline $\begin{array}{l}\text { Câmara Municipal de } \\
\text { Porto Alegre }\end{array}$ & $\begin{array}{l}\text { Câmara Municipal e de } \\
\text { Rio Grande }\end{array}$ & $\begin{array}{l}\text { Câmara Municipal e de } \\
\text { Santiago }\end{array}$ & $\begin{array}{l}\text { Câmara Municipal e de } \\
\text { Piratini }\end{array}$ \\
\hline $\begin{array}{l}\text { Todos os individuos de con- } \\
\text { dução livre de ambos os se- } \\
\text { xos que mediante salário } \\
\text { mensal tomam emprego de: }\end{array}$ & $\begin{array}{l}\text { moça de hotel ou de casa de } \\
\text { pasto e de hospedaria } \\
\text { cozinheiro } \\
\text { copeiro } \\
\text { hortelão } \\
\text { cocheiro } \\
\text { lacaio } \\
\text { ama de leite } \\
\text { ama seca } \\
\text { qualquer serviço doméstico }\end{array}$ & $\begin{array}{l}\text { E considerado criado e peão } \\
\text { para todo o efeito desta pos- } \\
\text { tura quem quer que sendo } \\
\text { de condição livre tomar me- } \\
\text { diante salário ocupação de: } \\
\text { moça de hotel ou casa de } \\
\text { pasto ou de hospedaria } \\
\text { cozinheiro } \\
\text { copeiro } \\
\text { hortelão } \\
\text { cocheiro } \\
\text { lacaio } \\
\text { ama de leite } \\
\text { ama seca e em geral para } \\
\text { qualquer serviço doméstico. } \\
\text { E para peão todo aquele que } \\
\text { se sujeitar para o serviço de } \\
\text { campo ou agrícola ou qual- } \\
\text { quer outro que não seja aci- } \\
\text { ma especificado. }\end{array}$ & $\begin{array}{l}\text { São considerados criados to- } \\
\text { dos os individuos de ambos } \\
\text { os sexos que, mediante sa- } \\
\text { lário, se colocarem na de- } \\
\text { pendência de outrem, como: } \\
\text { peão } \\
\text { cozinheiro } \\
\text { hortelão } \\
\text { lacaio } \\
\text { servente } \\
\text { ama seca } \\
\text { e em geral os que estiverem } \\
\text { obrigados por um contrato a } \\
\text { qualquer serviço doméstico } \\
\text { ou inerente à condição de } \\
\text { fâmulo. }\end{array}$ \\
\hline
\end{tabular}


No caso do contratado mudar de emprego ou perder a caderneta deve comparecer imediatamente à Secretaria da Câmara para fazer a notificação.

Os contratados que falsificarem cadernetas, ou se apresentarem sem elas nos empregos, são sujeitos a multas em dinheiro ou enquadrados nas penalidades específicas do código criminoso.

Deve-se esclarecer que o não cumprimento das cláusulas é sempre passível de multas pecuniárias, tanto para o contratado como para o contratador. 4

Rio Grande aprova o seu Regulamento de trabalho dos criados no mesmo dia em que a Câmara pelotense promulga o seu. O regulamento de Rio Grande tem vinte e sete artigos, porém muito pouco diferem, em substância, dos artigos postulados em Pelotas.

Salienta-se apenas alguns detalhes diferentes. $O$ artigo onze, para exemplificar, discrimina oito motivos para o contratador despedir o criado, sem aviso prévio:

1 Enfermidades que prive o criado de fazer o serviço;

2 Embriaguês;

3 Recusa ou imperícia para o serviço;

4 Negligência ou pouco asseio;

5 Injúrias, calúnias ou qualquer ofensa criminosa feita ao patrão ou pessoa de sua família;

6 Prática de atos imorais;

7 Infidelidade;

8 Ser causa de desordens na família, promovendo intrigas. 5

O artigo treze especifica o caso das amas de leite, estipulando que eias devem amamentar apenas a uma criança.

No artigo dezesseis aponta-se como deveres fundamentais do criado obedecer ordens de boa vontade e diligentemente e zelar pelos interesses dos patrões.

Os contratadores, segundo o artigo dezessete, devem tratar bem aos seus criados, fornecer-lhes alimentação e quarto 
para morar. Eles têm o dever de encaminhar os criados doentes para tratamento, por conta dos salários que ganham e para internamento em instituições, quando a doença é longa.

O artigo dezenove faculta ao empregador o direito de descontar do salário, do criado, o valor correspondente aos danos e prejuízos que tenha causado.

Observa-se que o temor das desordens e do abandono do trabalho, que pode seguir-se à libertação dos escravos, generaliza-se em todo o Rio Grande do Sul. Isto pode ser percebido através das cartas enviadas pelas Câmaras Municipais à regional. Veja-se o texto da carta da Câmara de Cacimbinhas enviada à Assembléia regional em Porto Alegre, no dia 30 de maio de 1888:

"Em conseqüência de ter sido promulgada a lei que extinguiu a servidão em nossa Pátria, há a urgente necessidade de preparar o espírito dos libertos para que se dignem ao trabaIho, mas como pelos meios persuasivos há dificuldade em conseguir-se este "desideratum" em nome da Câmara que presido, venho rogar a Vossa Excelência digne-se autorizar esta Câmara para, a exemplo da Capital, Rio Grande, Pelotas e Jaguarão, criar cadernetas para serem supridas aos criados e semelhantes a fim de, com este incentivo, pôr-se freios à vagabundagem que, nesta vila e seu município, tem aumentado consideravelmente."'6

Em 10 de novembro de 1888, o pedido vem da Câmara Municipal da Vila de São João Baptista de Camaquã, solicitando permissão para adotar provisoriamente o regulamento sobre criados da Câmara Municipal de Rio Grande. A urgência da legislação é tão palpável - segundo a missiva - que dispensa explicações a respeito. 7

Entre 1887 e 1889, quatro regulamentos de criados, com pequenas diferenças em alguns artigos, são adotados por diversos municípios gaúchos. (Ver quadro nং 3) 
Quadro n:3

Regulamento sobre o serviço dos criados.

\begin{tabular}{|c|c|c|c|}
\hline Município & $\begin{array}{l}\text { Data de } \\
\text { Aprovação da Lei }\end{array}$ & $\begin{array}{l}\text { Número } \\
\text { da Lei }\end{array}$ & $\begin{array}{l}\text { Número de } \\
\text { artigos }\end{array}$ \\
\hline Pelotas & $23-12-1887$ & 1628 & 11 \\
\hline Porto Alegre & $04-01-1888$ & 1645 & $\begin{array}{l}=\text { ao de } \\
\text { Pelotas }\end{array}$ \\
\hline Rio Grande & $05-01-1888$ & 1651 & 27 \\
\hline Jaguarão & $05-01-1888$ & 1652 & $\begin{array}{l}=\text { ao de } \\
\text { R. Grande }\end{array}$ \\
\hline Cachoeira & $13-12-1888$ & 1706 & $=11$ \\
\hline Passo Fundo & $19-12-1888$ & 1718 & $=11$ \\
\hline $\begin{array}{l}\text { Sta. Vitória } \\
\text { do Palmar }\end{array}$ & $26-12-1888$ & 1749 & $\begin{array}{l}\overline{\bar{C}} \text { ao de } \\
\text { Cachoeira }\end{array}$ \\
\hline Sta. Maria & $26-12-1888$ & 1750 & $\begin{array}{l}\overline{=} \text { ao de } \\
\text { Pelotas }\end{array}$ \\
\hline Itaqui & $03-04-1889$ & 1775 & $\begin{array}{l}\overline{\bar{a}} \text { ao de } \\
\text { Pelotas }\end{array}$ \\
\hline Sto. Ângelo & $03-04-1889$ & 1775 & $\begin{array}{l}=\text { ao de } \\
\text { Pelotas }\end{array}$ \\
\hline S. Luiz Gonzaga & $03-04-1889$ & 1775 & $\begin{array}{l}\overline{=} \text { ao de } \\
\text { Pelotas }\end{array}$ \\
\hline Quaraí & $03-04-1889$ & 1775 & $\begin{array}{l}\overline{\bar{a}} \text { ao de } \\
\text { Pelotas }\end{array}$ \\
\hline Gravataí & $15-06-1889$ & 1857 & $\begin{array}{l}=\text { ao de } \\
\text { Pelotas }\end{array}$ \\
\hline Cruz Alta & $28-06-1889$ & 1833 & $\begin{array}{l}\overline{=} \text { ao de } \\
\text { R. Grande }\end{array}$ \\
\hline Santiago & $28-06-1889$ & 1842 & 27 \\
\hline Piratini & $28-06-1889$ & 1843 & 19 \\
\hline
\end{tabular}


Deve-se salientar os modelos de regulamentos adotados em Santiago do Boqueirão e Piratini, que incluem, como criados, a todos que exerçam as funções de peão.

As posturas de Santiago contêm dois modelos de contrato, conforme segue:

Modelo n? 1

Contrato

Eu .......... abaixo assinado contratei hoje a $F \ldots \ldots \ldots \ldots$ por tempo indeterminado, para ........., vencendo por mês ........ rs. E para constar faço este que assino.

Santiago do Boqueirão .... de ..... de 18 .. (ass. o patrão)

(ass. o criado)

Modelo n: 2

Certificado

Certifico que $F \ldots \ldots \ldots$ se retirou hoje, por ............ e que o seu comportamento em minha casa foi ..........

\section{Data}

(Ass. do patrão) 8

O regulamento dos serviços dos criados, adotado em Piratini, contém 18 artigos, muito ricos em detalhes. Isto o torna um dos mais completos regularmentos em circulação. ${ }^{9}$

0 artigo sexto reza que o patrão especifique, na cadernedeta do criado, o motivo da despedida do emprego e qual a conduta assumida pelo criado ao longo do contrato. No artigo explica-se que a medida visa não prejudicar, com falsidades, a terceiros.

A preocupação do regulamento em proteger ao empregador transparece com nitidez no artigo número dez:

Se o contratado despedido, ou que se despedir, estiver devendo alguma quantia ao pa- 
trão e não puder pagá-la deverá ser declarado no atestado a importância do débito, sendo o novo ou subseqüentes contratadores obrigados a reter mensalmente, para entregar ao credor, a metade do salário ajustado, até o completo embolso da dívida constante do atestado; e assim não procedendo, incorrerá na multa de $8 \$ 000$ rs por cada mês de infração. O credor a proporção que for sendo embolsado, passará recibo na caderneta, levando o credor esses recibos ao registro. 10

No caso de falta de dinheiro dos criados ou peões, para pagar multas, devem, segundo o artigo dezoito, serem aprisionados. Cada dia na prisão abona $1 \$ 000$ rs da dívida. Nenhum contraventor pode permanecer preso por mais de 30 dias e a pena ficará sem efeito, quando o contraventor, ou alguém por ele, pagar a quantia correspondente ao tempo que faltar para o cumprimento da pena.

O regulamento proibe a vadiagem. Julga como vadio a todo o indivíduo que, não tenha indústria, renda, profissão ou emprego habitual, certo e honesto, de que possa subsistir.

O vadio recebe inicialmente aviso do Delegado para se empregar. Depois, em caso de reincidência, é multado e finalmente pode ser preso. Se o vadio não tiver meios para pagar a sua alimentação na prisão é obrigado a fazer serviços municipais. Neste caso, recebe a comida em troca do trabalho.

Em junho de 1888, registra-se, nos Anais da Assembléia Municipal de Porto Alegre, que o Presidente da Província aprovou a resolução da Câmara de nomear um fiscal para regularizar o serviço de criadagem do município.11 A atitude da Câmara Porto-alegrense faz suspeitar que, no caso dos regulamentos de serviços de criados, ocorrem desvios de comportamento dos patrões e seus subordinados.

De fato, a legislação trabalhista, que apareceu no Brasil, antes de 30 , foi, segundo Mozart Russomano, uma legislação lacunosa e inútil.

Infere-se do fato que os Regulamentos de Criados, embora aprovados pelas Câmaras Municipais, são de difícil aplicação e controle na realidade concreta. 
A discrepância entre legislação e praxis evidencia as contradições do modo de produção que se instala no sul, com a extinção da escravatura. Ela revela ainda os sintomas iniciais da problemática inserção do negro livre em uma sociedade, que tem a sua evolução histórica marcada pela exploração do trabalho negro escravo.

\section{CONCLUSÃO}

No dia 13 de maio de 1888, por instâncias de João Alfredo, a Princesa Isabel assina a Lei Áurea, com oposição de uma minoria de representantes dos partidos monárquicos.

O Presidente rio-grandense é o conservador Rodrigo de Azambuja Villanova. Ele esclarece em seu relatório que a Lei Aurea não produz perturbação na província. 12

Os conservadores gaúchos aceitam a abolição como uma homenagem aos princípios da humanidade. Apercebem-se, porém, que no Brasil, tal como sucedeu nos Estados Unidos, não se fez uma preparação do negro para a liberdade. Assim, teme-se que no país se reproduza a situação que a abolição trouxe para os norte-americanos. Lá, os negros libertos não trabalham mais, vivem em correrias de rapina e só voltam à vida produtiva, se pressionados pela miséria ou pelas autoridades constituídas.

Villanova aconselha aos libertos para permanecerem nos municípios onde residem, e onde será mais fácil conseguir trabalho. Sugere a formação de associações, em toda a província, para auxiliar aos escravos negros libertos. Villanova pretende com isso conseguir terras e empregos para os libertos, evitando conflitos sociais.

Julga-se que os regulamentos de trabalho de criados representam como tentativa do Estado, através das Câmaras Municipais, de obrigar ao trabalho, não apenas o negro liberto, porém os marginalizadios sociais de todas as raças.13 (Ver quadro $n \div 3$ )

A questão que se apresenta a partir desta problemática refere-se ao período e a forma como foi utilizada a legislação sobre o trabalho de criados. O conhecimento deste fato pode contribuir para o melhor entendimento das relações entre Estado/Capital/Trabalho no Rio Grande do Sul, no decorrer da República Velha. 


\section{NOTAS}

1 BAKOS, M. RS: ecravismo e abolição. Porto Alegre, Mercado Aberto, 1982. p. 74 .

2 Resumo geral dos quadros demonstrativos das condições de escravos inscritos na matrícula encerrada a 30 de março de 1887. In: Relatório com que o Exmo. Sr. Dr. Joaquim J. de Mendonça, 3 Vice-Presidente, passou a administração da Província do Rio Grande do Sul ao Presidente Exmo. Sr. Dr. Rodrigo de Azambuja Villanova em 27 de janeiro de 1887. Porto Alegre. Oficinas Tipográficas do Governador, 1888.

3 Coleção das Leis e resoluções da Província de $\mathbf{S}$. Pedro do Rio Grande do Sul. 1887-1889.

4 Lei 1628. In: Coleção de leis e resoluções da Província de São Pedro do Rio Grande do Sul. p. 91.

Grande do Sul. p.hDC4

5 Lei 1651, op. cit. p. 140.

6 BAKOS, M. op. cit. p. 73.

7 Ibidem, p. 73 .

8 Lei 1842 , op. cit. p. 58.

9 Lei 1843, op. cit. p. 62.

10 Ibidem, p. 69.

11 Anais da Câmara Municipal da Cidade de Porto Alegre, de janeiro a dezembro de 1888. Porto Alegre ,Tipografia do Jornal do Comércio, 1889. p. 2. 12 BAKOS, op. cit., p. 72.

13 Op. cit. nota 3.

\section{Bibliografia de apoio}

RUSSOMANO, Mozart. Legislação do Trabalho, Porto Alegre, Correio do Povo $3 / 10 / 1980$, p. 16.

FENELON, Dea. Levantamento e Sistematização da Legislação Relativa aos escravos no Brasil. In: Anais do VI Simpósio Nacional dos Professores Universitários de História. XLIV Coleção da Revista de História.

HARDMAN, Francisco Foot. História da Indústria e do trabalho no Brasil: das origens aos anos vinte: São Paulo, Global Ed. 1982.

\section{Pontifícia Universidade Católica do Rio Grande do Sul Departamento de História Porto Alegre - Brasil}

